\title{
Analysis of the Stabilization System of Mimbot Biped
}

\author{
M.E. Escobar*¹, H. Rubio ${ }^{2}$, J.C. García-Prada ${ }^{3}$ \\ 1,2,3 Departamento de Ingeniería Mecánica. Universidad Carlos III de Madrid. \\ Av. Universidad 30, 28911. Madrid. Spain. \\ *mescobar@ing.uc3m.es
}

\begin{abstract}
Mimbot robot consists of a mechanical system with one degree of freedom activated by a single motor; this robot is capable of simulating the human gait. Mimbot has three essential mechanisms: the Chebyshev mechanism, the pantograph mechanism and a stabilization system. The studied mechanism is an articulated system of links used in the leg of of the Mimbot biped robot. The technology used in the Mimbot biped is characterized by keeping these design conditions; using a mechanical system based on classical mechanics, the biped must reproduce the trajectory of human gait, energy consumption should be minimal and the prototype should be a low-cost robot. The role of the original stabilization system is to guide the foot to provide support for both legs; however, the position of the foot is not completely parallel to the support surface, which causes variations in the trajectory of the mass center of the biped, causing loss of stability. This paper presents a study of stability in the sagittal plane of the robot, adding a new mechanism that ensures that the stabilizer link is parallel to the ground at all times. Finally, a study of the kinematic and dynamic behavior generated by the modification has been carried out through an analytical model created by Adams $®$ software.
\end{abstract}

Keywords: robot, stabilization, kinematic and dynamics of mechanism.

\section{RESUMEN}

El robot bípedo Mimbot es un dispositivo mecánico de un grado de libertad accionado por un solo motor y capaz de emular el movimiento del paso humano. El Mimbot cuenta con tres mecanismos esenciales: mecanismo de Chebyshev, mecanismo tipo pantógrafo y un sistema de estabilización. La tecnología empleada en el Mimbot bípedo se caracteriza por mantener estas condiciones de diseño; utilizando un sistema mecánico basado en la mecánica clásica, el bípedo reproduce la trayectoria de la marcha humana, el consumo de energía debe ser mínimo y el prototipo debe ser un robot de bajo costo. El sistema de estabilización original busca proporcionar cierta orientación al pie para que sirva de apoyo al bípedo; sin embargo, no logra posicionar el pie completamente paralelo a la superficie de apoyo, lo cual ocasiona variaciones extensibles en la trayectoria del centro de masas del bípedo originando la consecuente pérdida de estabilidad. Este artículo plantea el estudio de la estabilidad, en el plano sagital del robot propone la inserción de un nuevo mecanismo que asegura que el eslabón estabilizador esté en todo momento paralelo al suelo. Finalmente se efectúa un estudio del comportamiento cinemático y dinámico generado por esta modificación, mediante un modelo analítico, implementado en el software Adams.

\section{Introduction}

Research on bipedal robots is booming from the theory of bipedal locomotion [1][2][3] to present day, bipeds that simulate human morphology with numerous links and joints driven by actuators [4][5][6]. The main disadvantage of such complex systems is their high weight and high power consumption [7]. For this reason, research needs to create systems based on classical mechanisms which are capable of simulating the trajectory of the human gait and have minimal energy consumption and cost. Professor Ceccarelli and his team from the Laboratory of Robotics and Mechatronic (LARM) have been working towards this goal; first with the EP-WaR II biped [8] and more recently with the leg designs of Caluma [9][10] (humanoid low-cost robot). With this in mind, Mimbot was created. It is a biped capable of simulating the human gait with just a single degree of freedom, activated by a motor [11][12]. The main objective of this research was to pioneer a change in the basic mechanism of the original Mimbot which provided the necessary stability in the sagittal plane to develop the gait. Therefore, this research developed a model, using Adams $\AA$ software, to determine the actual cause of instability. The results could then be incorporated into a new 
stabilization system, correcting the inappropriate movement of the biped.

\section{Description of Mimbot}

Mimbot biped [11] is a mechanical system with one degree of freedom which is able to emulate the human gait. It is based on a combination and adaptation of classical mechanisms: Chebyshev, pantograph and stabilization systems.

As shown in Figure 1(a), the Chebyshev mechanism is located in the upper section of the biped and is composed of three jointed links. These links convert the rotary motion provided by the motor to the input crank into an output movement executed by the rod, as can be seen from point $B$ of Figure 1(a). This is characterized by a closed trajectory with a section that is approximately rectilinear and has constant speed.

The lower end of the rod (B) in the Chebyshev mechanism is the point of coupling or input in the pantograph mechanism and stabilization system. The pantograph mechanism is located in such a way that point $A$ describes a trajectory reversed and enlarged with respect to the input.

The combination of the mechanisms illustrated in Figure 1(a) shows the outline of the leg of the biped and how it provides support for the structure. The foot is included, link A-C, which depends directly on the stabilization system.

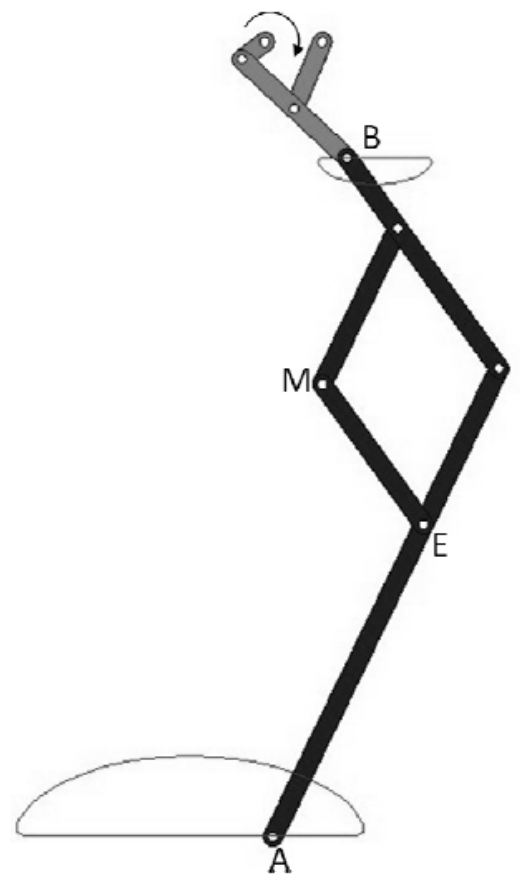

a)

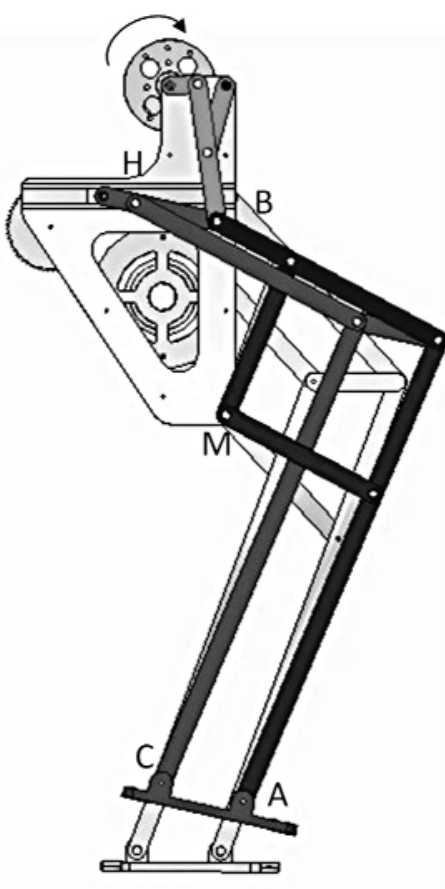

b)

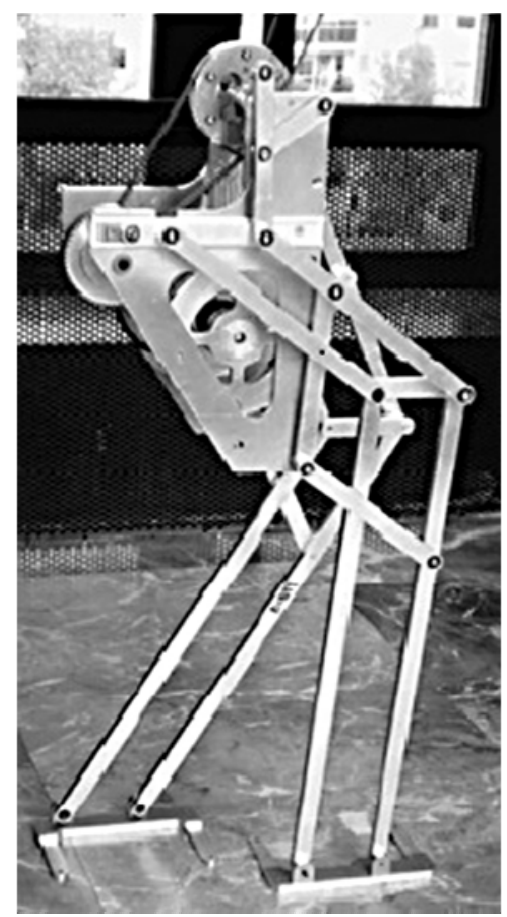

c)

Figure 1. Mimbot Submechanisms: a) fibrillar pattern, b) virtual model, c) initial prototype. 
The final part of the stabilization system comprises a set of links that run parallel to the two longest links of the pantograph, which ensures the stabilizer link and the foot of the biped remain parallel, as shown in Figure 1(b).

The stabilizer link, defined by points $H$ and $B$ in Figure 1(b), determines the orientation of the foot as it is fixed at one end to the crank Chebyshev mechanism (B), and at the other end (point $H$ ), it glides down the slide located in the hip of the biped. This configuration helps keep the foot at a certain bias while in flight and retain a horizontal position during the stance phase. This is due to the slide alignment while stretched, being almost straight during the trajectory described in point $B$.

The step of the biped is characterized by a closed path, composed of two phases. The first phase has an almost straight path, which corresponds to the exact moment when the foot is supported by the floor. The second phase (while the foot is in the air) has an almost ecliptic path. This happens in each leg alternately, as they are geometrically identical, and their input cranks are $\pi$ radians out of phase with each other. Therefore, one complete cycle of movement (one rotation of the engine) is composed of two steps, one by each leg.

\section{Stabilization System}

The current stabilization system allows the stabilizer to link a rotation about point $B$, represented by angle a (ranging from $0{ }^{\circ}$ to 12.93 $\left.{ }^{\circ}\right)$ for the dimensions and condition of the prototype built, Figure 1(c). Insomuch as the stabilizing system ensures the stabilizer link and the foot remain in parallel, the slope created between the stabilizer link and the horizontal accurately replicates the foot (Figure 2).

Angle a obtains its maximum value at the start of the step. It is maintained during the flight phase and decreases until it reaches its minimum value when point $A$ makes contact with the surface.
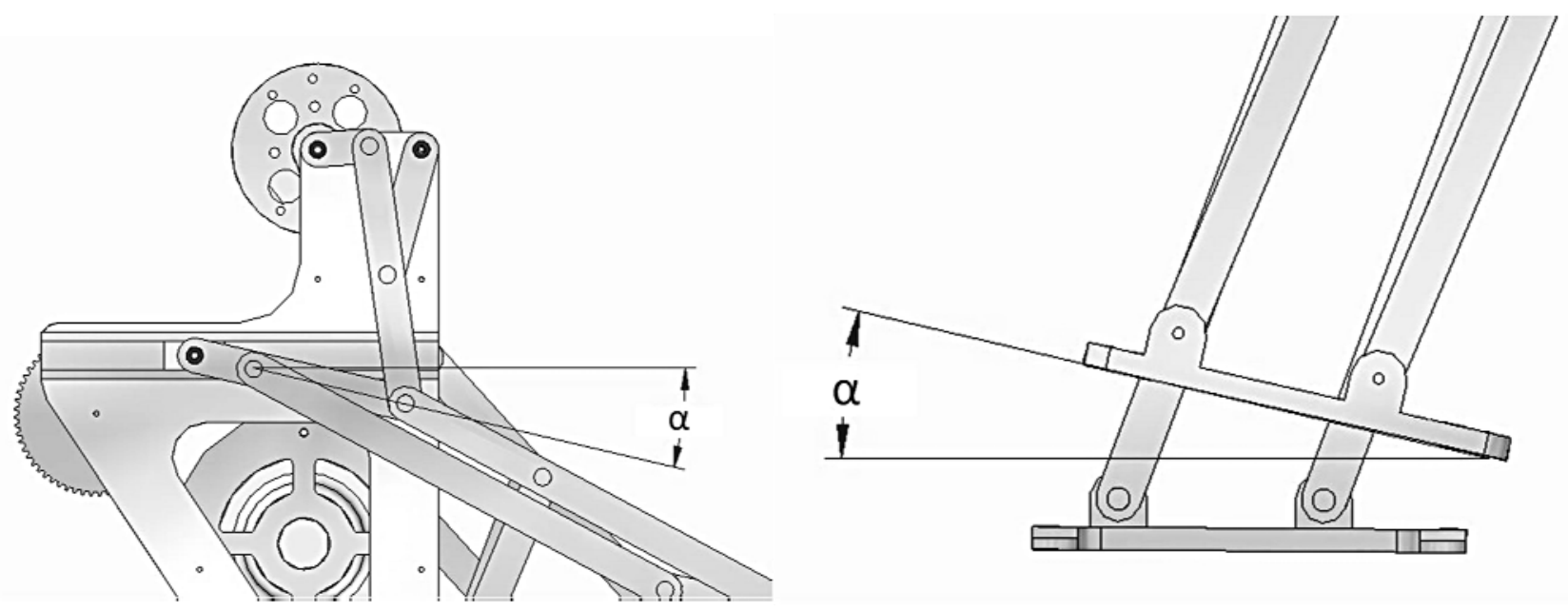

Figure 2. Representation of angle $\alpha$ in the model. 


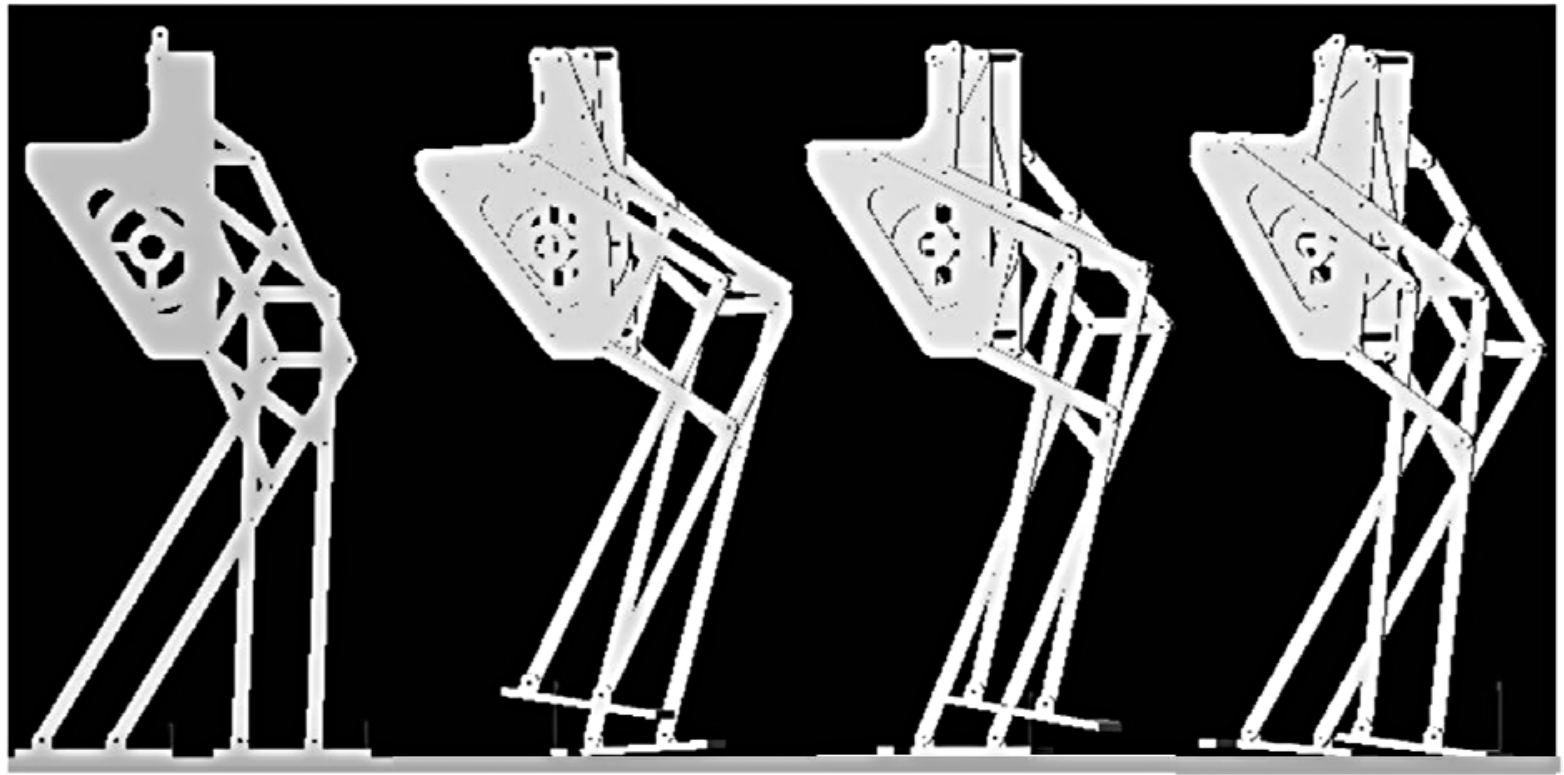

Figure 3. Development of a step. Double support - Beginning of the step - Flight stage - Beginning of double support.

The existence of two critical moments for stability in the sagittal plane can be determined using the dynamic analysis software Adams to study the behavior of a virtual model that has the same dimensions and dynamic characteristics of the actual prototype biped Mimbot. These are at the start and the end of the step. Figure 3 shows that at the beginning of the step, the biped has a slight slant in the opposite direction of the motion, which causes the biped to be supported solely on the back of the foot (its heel), giving rise to a rebound.

At the beginning of the double support phase, the foot that ended the flight period makes an angle $\alpha$ with the ground, which is greater than zero degrees, because the mechanism Chebyshev point $B$ is not in quasi-straight stretch of its trajectory, and therefore, the stabilizer link has an inclination equal to $\alpha$. At this moment, the opposite foot ( $\pi$ radians out of phase) is in the startup phase of flight, thus, its corresponding stabilizer link also has a position with an angle a (which will not be zero). The reduced area of the feet in contact with the surface during the double support period causes a moment in which the biped oscillates on the balls of the feet, causing the center of mass to move sharply. This leads to a loss of stability in the sagittal plane and hampers the ability to forge a straight path.

\section{Variation in stability}

Considering that the tilt of the foot causes an imbalance at the beginning and end of the step, it is necessary to develop a system that can provide the necessary horizontal support to stabilize the link.

To achieve this, a double slide system was added to the hip of the biped which was able to break down the fluctuating movements of the stabilizer into straight movements. Figure 4 shows the proposed stabilization system. With this new mechanism, the foot remained completely horizontal during the step cycle ( $\alpha$ $(\Theta)=0$. 

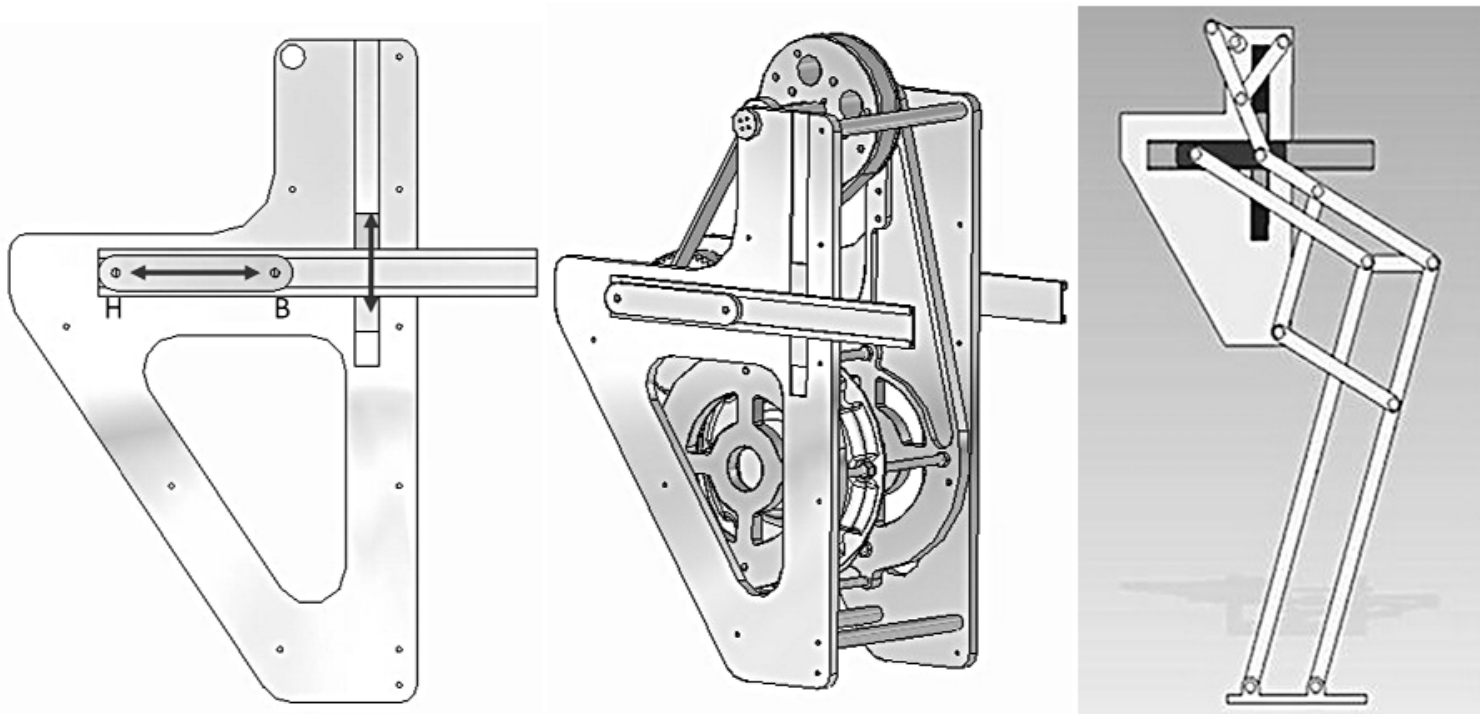

Figure 4. Provision of a double valve mechanism in the virtual model.
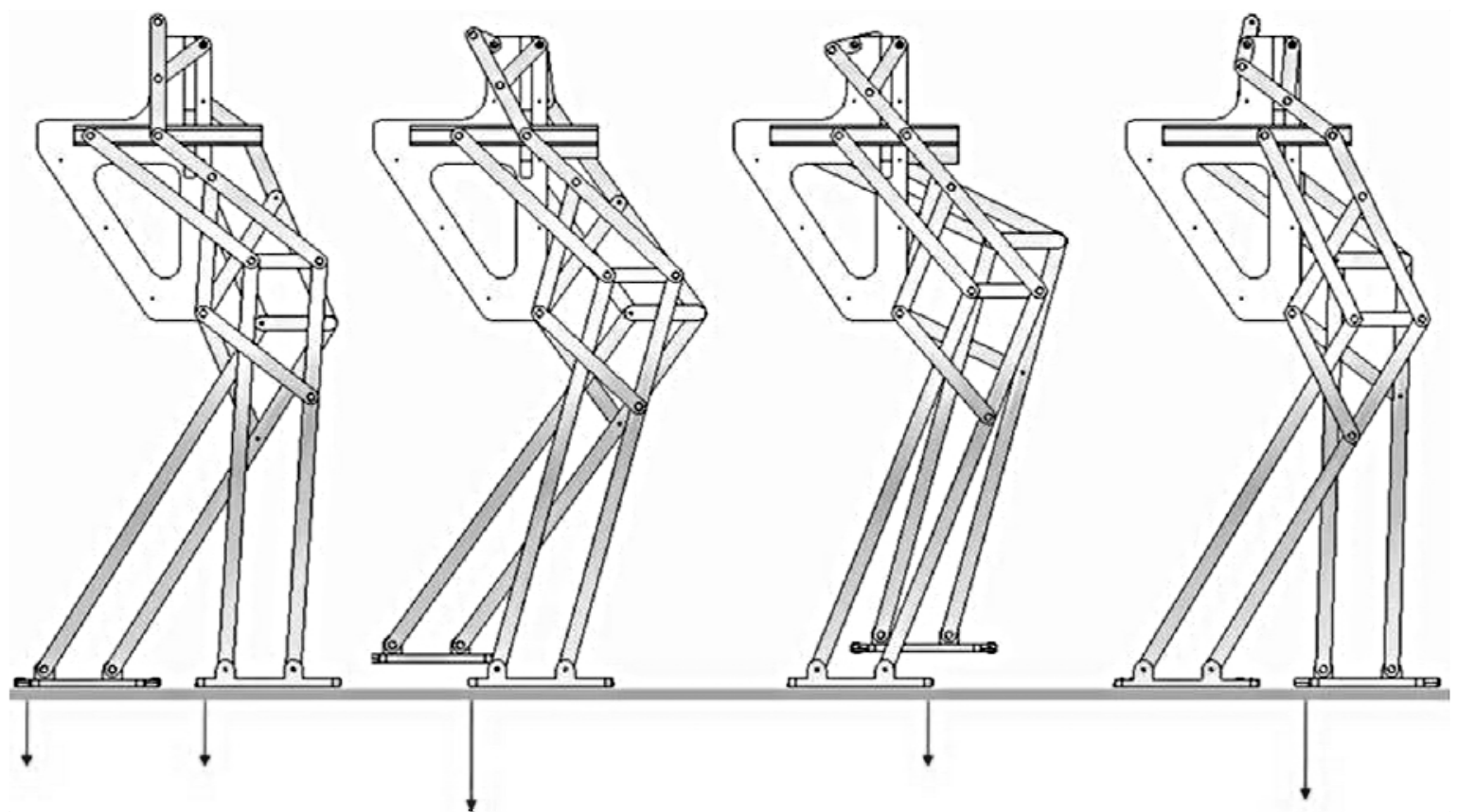

Figure 5. Mimbot with the new stabilization system. Phases: double support, start of the foot lifting, foot descent, contact with the ground. 
At point $\mathrm{H}$, a vertical scroll can be achieved with the implementation of the new stabilization mechanism. This prevents rotation at point $B$, and the stabilizer links can only move vertically or horizontally, without affecting the trajectory described by the Chebyshev mechanism as shown in Figure 4.

The trajectory of point $A$ follows the characteristic curve of the Chebyshev mechanism, but in this case there are no differences between the trajectory of point $A$ and its counterpart in the stabilization system (C): both points have the same trajectory, which ensures a parallel relationship between the foot and the support surface of the biped.

Figure 5 shows a sagittal cross section of four moments of one step of Mimbot robot (in sequence) with the new stabilizing mechanism. This starts with the period of dual support, continuing with the rise and fall of the foot, and finally returning to the double support, thereby completing one step.

\section{Results}

As angle $\alpha$ is a function of the horizontal projections of links $C E$ and $C B$, its behavior is known by Equation 1. The evolution of the position of the foot in relation to the position of the input crank $\Theta$ (in the original model of the Mimbot (Figure 3) during a complete cycle is illustrated in Figure 6. This graph shows the initial position of the foot when the input crank of the engine is at zero degrees $\left(\theta=0^{\circ}\right)$. This is the point at which the foot is at the peak of its trajectory above ground and coincides with the moment at which the slope of the foot is at its maximum ( $\alpha=12.93$ $\left.{ }^{\circ}\right)$. It was observed that angle a grew almost linearly during the beginning of the flight stage of the foot (lifting the foot), reaching its maximum value when the input crank has a value of $\theta=0$ degrees, then decreased almost linearly (foot drop) to its minimum value, to remain almost constant ( $\alpha$ $\approx 0.5^{\circ}$ ) during the support phase.

$$
\cos \alpha=\frac{C E_{X}-C B_{X}}{M E}
$$

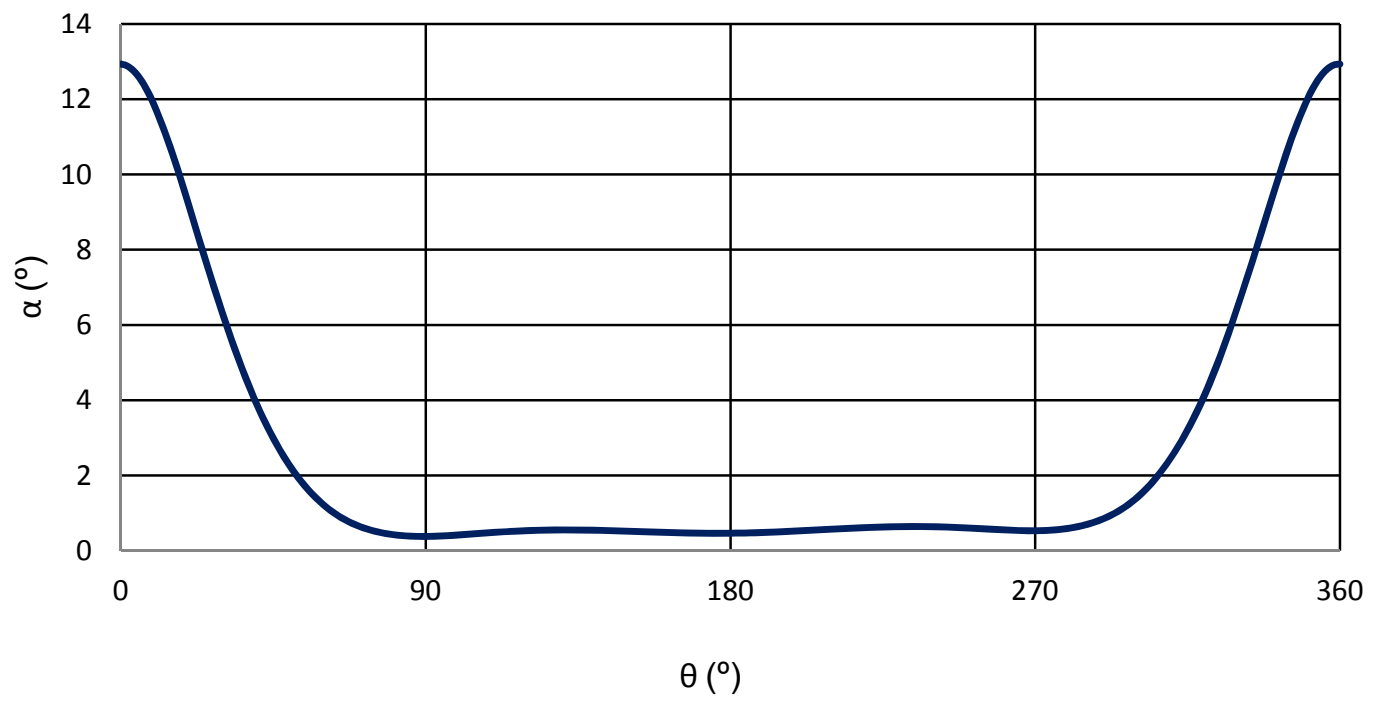

Figure 6. Angle evolution a. 
As a result of the tilt in the stabilizer in the original Mimbot model, it can be confirmed that points $A$ and $C$ make a similar path during the stance phase, but different paths during the flight phase, as shown in Figure 7(a) Incorporating the new stabilizer system in the hip (and comparing the movement at significant points of the sole of the foot $-A$ and $C$-), means the curves make similar progress, as shown in Figure $7(b)$. This ensures that the parallel relationship between the sole of the foot, the stabilizer link and the ground or support surface is maintained at all times.

The new stabilizer prevents the initial contact of double support being made by only a very small area, as it is with the toe, decreasing significantly the characteristic oscillation of the original Mimbot which weakened the stability in the sagittal plane. This can be verified by detailing the movements of a fixed point or "marker" on the hip of the biped, in each of the three planes. In Figure 8(d), the course of the coordinate axes used in the virtual model (simulated in Adams ${ }^{\circledR}$ ) is shown.
Figure $8(a)$ shows the temporal progression of the "marker" on shaft $X$ for both models; the original Mimbot and the new model with the stabilizer. Itdemonstrates that, with the insertion of the double sliding mechanism, the movements fluctuate less, but the models have similar behaviors.

Figure 8(b) depicts the temporal progression of the "marker" in the $Y$ axis (sagittal axis).In this representation, the variations are significant because the new stabilizer means there is a slight decrease in the average position of the hip of the biped in the sagittal plane. However, the movement is periodic and stable in comparison with the irregular path that the "marker" of the original Mimbot model followed.

The temporal evolution of the "marker" in the $Z$ axis is shown in Figure 8(c). It shows that the modified model, with the double slide, is able to maintain its course, while the original model deviates significantly from its intended course. This deviation from its intended path is caused by the rebound effect- the direction is determined by the initial layout of the feet and the size of the deviation depends on the speed.
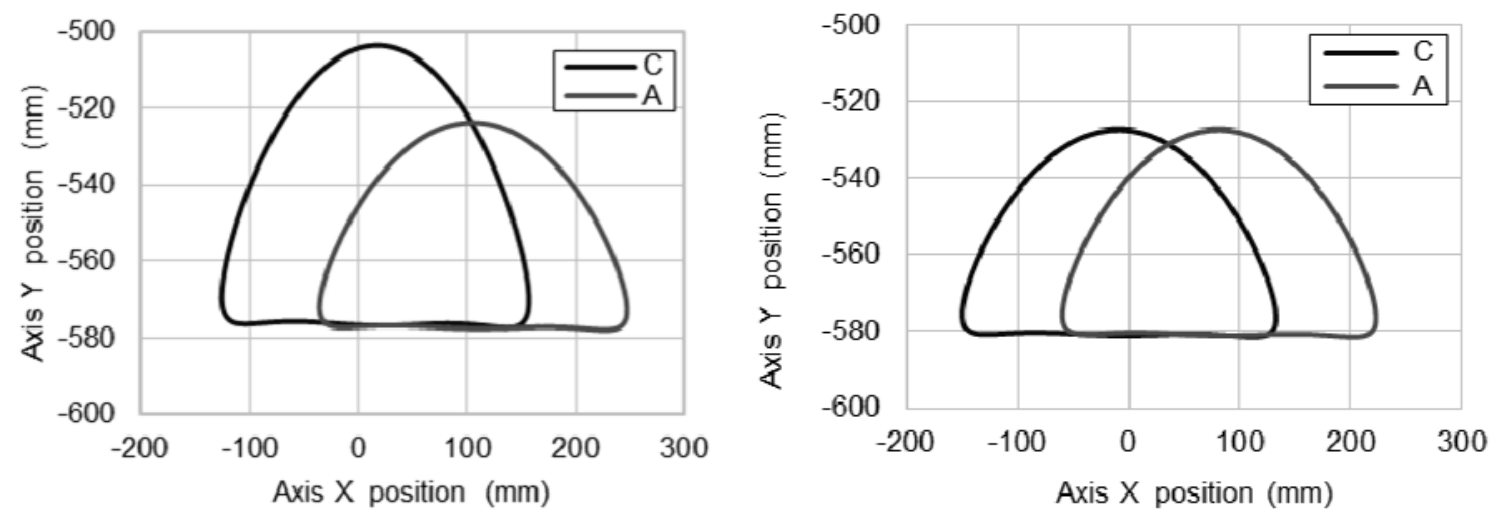

Figure 7. Trajectory of points $\mathrm{A}$ and $\mathrm{C}$ of the foot. a) Original Model. b) Modified Model. 

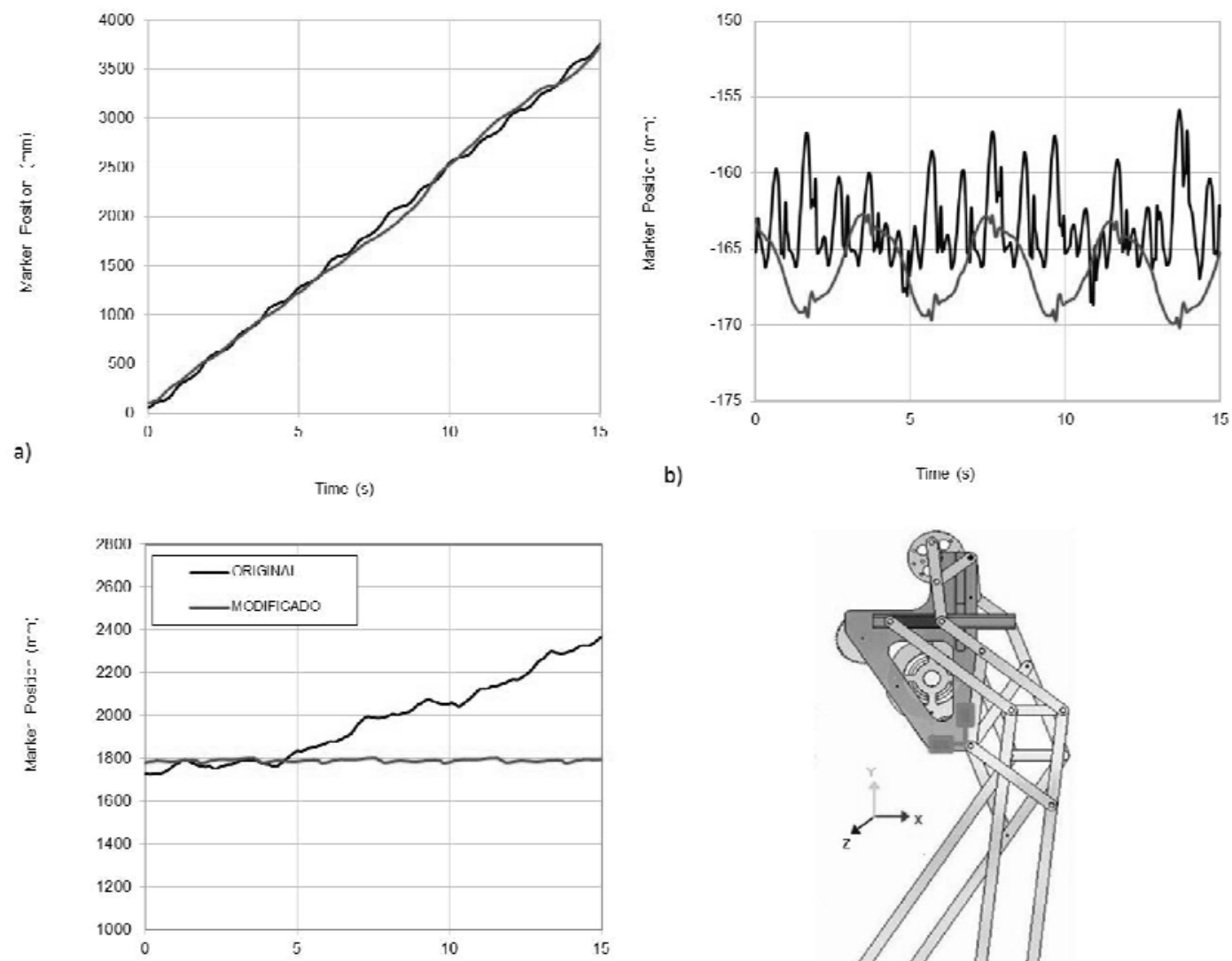

c)

$$
\text { Timo (s) }
$$

b)

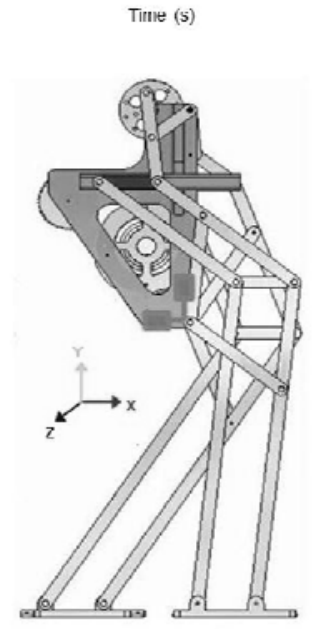

Figure 8. Comparative paths of a marker on the hip. In the (a) X, (b) $Y$ and (c) Z axes.

\section{Conclusions}

This paper presents a model of Mimbot biped in Adams $₫$. It is a robot developed using low-cost technology. It has a basic mechanical system which consists of two geometrically equal legs. This robot is the result of combining classical mechanisms (Chebyshev, pantograph and stabilization system).

In the original model, certain instabilities were present that were believed to be due to mistakes in the way contact was simulated in Adams ${ }^{\circledR}$. It was done in such a way that the foot to ground contact did not reproduce the true movement accurately. After making a prototype of Mimbot, relevant tests were undertaken, proving the original hypothesis to be correct. Nevertheless, at high speed, the prototype became unstable, and did not demonstrate the dynamic behavior expected.

A new Mimbot model in Adams ${ }^{\circledR}$ was designed with much greater care which paid particular attention to foot to ground contact and weight distribution. This model gave similar results to those of the prototype. Given that the instability remained, albeit much reduced, analysis was undertaken to determine the cause of this dysfunction, and was subsequently corrected by redesigning the stabilization system, as shown in Figure 4.

Foot to ground contact was studied (the angle of inclination of the foot and relative positions at all phases of the step), and it was noted that in some instances, during both the takeoff and landing of 
the foot, it connected with the ground at just one point, which produced more shocks and greater rebound.

The shocks generated forward and backward oscillations. This was an effect that was corrected for average speeds of forward motion, and increased at higher speeds, up to a speed at which they collapsed.

The rebound effect was due to a deviation from Mimbot's expected trajectory. The direction of deviation was dependent on the initial layout of the feet, and the size of the deviation depended on the speed.

The results obtained from displacement curves show that the stabilizing mechanism has changed, the trajectory of point $C$ being exactly equal to the trajectory described for the next joint $(A)$, which reduces imbalances in the mechanism, thereby maintaining the orientation of the foot as parallel to the ground at all times.

After studying the two models of the Mimbot biped developed in Adams $\AA$, it can be concluded that both are able to develop a correct gait, but the new model (with the double slide stabilization mechanism) improves the stability of the original model.

\section{Acknowledgements}

Acknowledgments are due to the Spanish CICYT Project DPI2006-15443-C0-JCGPRADA.

\section{References}

[1] T. McGeer, "Passive dynamic walking," The International Journal of Robotics Research, vol. 9, 1990, pp. 62-82.

[2] T. McGeer, "Passive walking with knees," 1990 IEEE International Conference on Robotics and Automation, 1990. Proceedings., 1990, p. 1640-1645.

[3] R.M. Alexander, "A model of bipedal locomotion on compliant legs.," Philosophical transactions of the Royal Society of London. Series B, Biological sciences, vol. 338, 1992, pp. 189-98.

[4] S. Collins and A. Ruina, "A bipedal walking robot with efficient and human-like gait," Robotics and Automation, 2005. ICRA 2005. Proceedings of the 2005 IEEE International Conference on, 2005, p. 1983-1988.

[5] S. Haddadin, T. Laue, U. Frese, S. Wolf, A. AlbuSchäffer, and G. Hirzinger, "Kick it with elasticity: Safety and performance in human-robot soccer," Robotics and Autonomous Systems, vol. 57, 2009, pp. 761-775.

[6] D. Hobbelen and M. Wisse, "Ankle joints and flat feet in dynamic walking," Climbing and Walking Robots, 2005, p. $787-800$.

[7] Y. Sakagami, R. Watanabe, C. Aoyama, and S, "The intelligent ASIMO: System overview and integration," Intelligent Robots and Systems, 2002. IEEE/RSJ International Conference on, vol. 3, 2002, pp. 2478-2483.

[8] G. Figliolini, "Walking programming for an electropneumatic biped robot," Mechatronics, vol. 9, 1999, pp. 941-964.

[9] N. Rodriguez, G. Carbone, M. Ceccarelli, and I, "Design Evolution of Low-cost Humanoid Robot CALUMA," 12th IFToMM wordl Congress, 2007.

[10] C. Tavolieri, E. Ottaviano, M. Ceccarelli, and A. Di, "Analysis and Design of a 1-DOF Leg for Walking Machines," Proceedings of RAAD'06, 2006.

[11] J. Meneses, H. Rubio, C. Castejón, E. Ottaviano, and M. Ceccarelli, "Modelo cinemático del robot bípedo "Mimbot"," IX Congreso Iberoamericano de Ingeniería Mecánica., Las Palmas de Gran Canaria. España: 2009, p. 8.

[12] H. Rubio, J. Meneses, C. Castejon, A. Jardon, A. Giménez, and J.C. García-prada, "Mechanical Desing of walking robot Mimbot. Parametric model and gait analysis.," 12th International Conference on climbing and walking robots.CLAWAR 2009, Istambul. Turkey: 2009, pp. 1-9. 